\title{
Lesion topographies in multiple sclerosis diagnosis
}

\author{
A reappraisal \\ OPEN
}

Georgina Arrambide, $\mathrm{MD}, \mathrm{PhD}^{*}$

Mar Tintore, MD, PhD* Cristina Auger, MD Jordi Río, MD, PhD Joaquín Castilló, MD, $\mathrm{PhD}$

Angela Vidal-Jordana, MD, PhD

Ingrid Galán, MD

Carlos Nos, MD

Manuel Comabella, MD, $\mathrm{PhD}$

Raquel Mitjana, MD Patricia Mulero, MD Andrea de Barros, MD Breogán RodríguezAcevedo, MD

Luciana Midaglia, MD Jaume Sastre-Garriga, $\mathrm{MD}, \mathrm{PhD}$

Alex Rovira, MD†

Xavier Montalban, MD, $\mathrm{PhD} \dagger$

Correspondence to Dr. Montalban: xavier.montalban@cem-cat.org

Editorial, page 2308

Supplemental data at Neurology.org

\section{ABSTRACT}

Objectives: To assess the contributions of cortico-juxtacortical and corpus callosum lesions to multiple sclerosis diagnosis and to compare the value of $\geq 1$ vs $\geq 3$ periventricular lesions in clinically isolated syndromes (CIS).

Methods: Step 1: We evaluated lesion topography classifications in 657 patients with CIS with stepwise Cox proportional hazards regression models considering second attack as the outcome. Step 2: We established 2 dissemination in space (DIS) versions according to the periventricular lesion cutoffs of $\geq 1$ and $\geq 3$ and assessed their performance at 10 years with second attack as the outcome, first individually and then combined with dissemination in time (DIT) in all cases ( $\mathrm{n}=326)$, by age, and by CIS topography.

Results: Step 1: The models (hazard ratios [95\% confidence interval]) favored $\geq 1$ over $\geq 3$ periventricular lesions (2.5 [1.7-3.6]) and cortico-juxtacortical over juxtacortical lesions (1.4 [1.01.8]). Callosal lesions were not selected. Step 2: DIS specificity with $\geq 1$ periventricular lesions was slightly lower than with $\geq 3$ (59.1 vs 61.4) and the same after adding DIT (88.6). Regarding age, $\geq 3$ periventricular lesions improved DIS specificity over $\geq 1$ lesions in the 40-49 years of age bracket (66.7 vs 58.3). This difference disappeared when adding DIT (83.3). Optic neuritis had a similar pattern when evaluating CIS topographies.

Conclusions: Our results comply with the Magnetic Resonance Imaging in Multiple Sclerosis (MAGNIMS) consensus recommendation of combining cortical and juxtacortical lesions into a single term when possible. Concerning periventricular lesions, maintaining the current $\geq 1$ cutoff in the McDonald criteria does not compromise specificity in typical CIS cases, but attention should be paid to older patients or optic neuritis cases. Neurology ${ }^{\circledR}$ 2017;89:2351-2356

\section{GLOSSARY}

$\mathbf{C C}=$ corpus callosum; $\mathbf{C I S}=$ clinically isolated syndrome; $\mathbf{C J C}=$ cortical and juxtacortical; $\mathbf{D I R}=$ double inversion recovery; DIS = dissemination in space; DIT = dissemination in time; EDSS = Expanded Disability Status Scale; FLAIR = fluidattenuated inversion recovery; Gd = gadolinium; JC = juxtacortical; MAGNIMS = Magnetic Resonance Imaging in Multiple Sclerosis; $\mathbf{M S}$ = multiple sclerosis; $\mathbf{P V}=$ periventricular; $\mathbf{S C}=$ spinal cord.

Recently, an expert opinion consensus on proposed modifications to the multiple sclerosis (MS) diagnostic criteria suggested the increase of periventricular (PV) lesions from $\geq 1$ to $\geq 3$ and the inclusion of cortical, optic nerve, and symptomatic lesions for determining dissemination in space (DIS). ${ }^{1}$ Previous publications showed the relevance of lesion topographies for MS diagnosis ${ }^{2,3}$ or reassessed the role of PV lesion number. ${ }^{4}$ Regarding cortical lesions, they can be identified using nonconventional MRI and were proposed as part of the DIS criteria before, ${ }^{5}$ but interobserver variability is high. ${ }^{6}$ In this sense, the expert opinion consensus proposed

\footnotetext{
*These authors contributed equally to this work.

$\dagger$ These authors contributed equally as principal investigators.

From Servei de Neurologia-Neuroimmunologia, Centre d'Esclerosi Múltiple de Catalunya (CEMCAT) (G.A., M.T., J.R., J.C., A.V.-J., I.G., C.N., M.C., P.M., B.R.-A., L.M., J.S.-G., X.M.), and Magnetic Resonance Unit, Department of Radiology (IDI) (C.A., R.M., A.d.B., A.R.), Vall d'Hebron Institut de Recerca, Hospital Universitari Vall d'Hebron, Universitat Autònoma de Barcelona, Spain; and Division of Neurology (X.M.), St. Michael's Hospital, University of Toronto, Canada.

Go to Neurology.org for full disclosures. Funding information and disclosures deemed relevant by the authors, if any, are provided at the end of the article. The Article Processing Charge was funded by Fondo de Investigación Sanitaria of the Ministry of Economy and Competitiveness of Spain (grant PI14/ 01439 awarded to X.M.).

This is an open access article distributed under the terms of the Creative Commons Attribution-NonCommercial-NoDerivatives License 4.0 (CC BY-NC-ND), which permits downloading and sharing the work provided it is properly cited. The work cannot be changed in any way or used commercially without permission from the journal.
} 
combining cortical and juxtacortical (JC) lesions into a single term (CJC). Finally, corpus callosum (CC) lesions are common in MS but do not appear to contribute to the diagnosis.?

Therefore, the objective of this study was to assess the contributions of CJC and CC lesions to MS diagnosis and to compare the value of $\geq 1$ vs $\geq 3$ PV lesions, additionally stratified by age or clinically isolated syndrome (CIS) topography, in CIS.

METHODS Study cohort. This study was based on a longitudinal, open CIS cohort at the MS Centre, Vall d'Hebron University Hospital, Barcelona, Spain, following a protocol described elsewhere. ${ }^{3,8}$ Briefly, we included patients $<50$ years of age first seen within 3 months of the CIS. We recorded demographic data, CIS topography, presence of oligoclonal bands, and disability according to the Expanded Disability Status Scale (EDSS) at baseline, and performed follow-up visits every 3-6 months assessing for relapses and disability according to the EDSS measured during stability periods. Concerning additional MRI acquisition and analysis for this study, transverse or sagittal 3D double inversion recovery (DIR) sequences were performed since 2010. One of two experienced neuroradiologists (C.A., A.R.) blinded to clinical follow-up assessed the MRI scans during the daily clinical practice. In doubtful cases, the final analysis was based on their consensus opinion. They scored the number and location of lesions on T2-weighted images and the number of gadolinium (Gd)-enhancing lesions on brain MRI. From 2006, we recorded the presence of CC lesions on T2-fluid-attenuated inversion recovery (FLAIR) sagittal sequences prospectively in the CIS database. We constructed the CJC variable by combining supratentorial JC and intracortical lesions and assessed it on DIR and T2-FLAIR images. Importantly, we defined PV lesions as

\begin{tabular}{|c|c|c|}
\hline \multirow[t]{2}{*}{ Baseline characterist } & \multirow[b]{2}{*}{ Step $1(n=657)$} & \multirow[b]{2}{*}{ Step $2(n=326)$} \\
\hline & & \\
\hline Female, n (\%) & $437(66.5)$ & $227(69.6)$ \\
\hline Mean (SD) age, y & $32.2(8.0)$ & 31.5 (7.9) \\
\hline \multicolumn{3}{|l|}{ CIS topography, $\mathrm{n}(\%)$} \\
\hline Optic nerve & 219 (33.3) & 92 (28.2) \\
\hline Brainstem & $179(27.2)$ & $92(28.2)$ \\
\hline Spinal cord & $180(27.4)$ & 101 (31.0) \\
\hline Other & 79 (12.0) & 41 (12.6) \\
\hline OB present, n (\%) & 335 (59.3) & 211 (72.5) \\
\hline Abnormal baseline brain MRI, $n$ (\%) & 496 (75.5) & $293(89.9)$ \\
\hline Abnormal baseline SC MRI, $n(\%)^{b}$ & $172(52.3)$ & $76(66.1)$ \\
\hline Gd enhancement on brain MRI, $n$ (\%) & $191(29.1)$ & $127(39.0)$ \\
\hline Gd enhancement on SC MRI, $n(\%)^{b}$ & $54(16.4)$ & $28(24.3)$ \\
\hline Mean (SD) follow-up, y & $6.5(4.2)$ & $9.0(3.8)$ \\
\hline DMT before second attack, n (\%) & $184(28.0)$ & 101 (31.0) \\
\hline
\end{tabular}

Abbreviations: CIS = clinically isolated syndrome; DMT = disease-modifying treatment; $\mathrm{Gd}=$ gadolinium; $\mathrm{OB}=$ oligoclonal bands; $\mathrm{SC}=$ spinal cord.

${ }^{a}$ OB: $\mathrm{n}=565$ in step 1, $\mathrm{n}=291$ in step 2 .

bSC MRI: $\mathrm{n}=329$ in step 1, $\mathrm{n}=115$ in step 2 . those in contact with the lateral or third ventricles, but not when in contact with the fourth ventricle. CC lesions were not considered PV unless they extended outside the CC, and we only considered a lesion to be callosal when identified in 3-5 midsagittal images (with a 3-mm slice thickness), therefore excluding those that were paracallosal and thus considered PV. Finally, from 2007, we scored lesion number and presence of Gd enhancement on spinal cord (SC) MRI systematically.

Experimental design. Step 1. To evaluate the effect of individual lesion topographies, we selected patients with sufficient information on baseline brain MRI to assess DIS and dissemination in time (DIT) according to the 2010 McDonald criteria ( $\mathrm{n}=657)$. Next, we established the following lesion topography classifications: $\geq 1$ $\mathrm{PV}, \geq 3 \mathrm{PV}, \geq 1 \mathrm{JC}, \geq 1 \mathrm{CJC}, \geq 1 \mathrm{CC}, \geq 1$ infratentorial, and $\geq 1$ SC. We then ran univariable and multivariable Cox proportional hazards regression models using a forward and backward stepwise analysis with likelihood ratio statistics ( $p$ value for entry of 0.05 and $p$ value for removal of 0.1 ) considering second attack as the outcome during the total follow-up time. We added a "missing" category for patients with no recorded SC or CC lesions. We used bootstrap resampling to cope with overfitting.

Step 2. To evaluate performance, we selected cases from step 1 with a minimum follow-up of 10 years or a second attack within 10 years of the CIS $^{9}(n=326)$. We constructed the 2010 DIS criteria ${ }^{10}$ taking into account the symptomatic lesions ${ }^{11,12}$ and using the CJC topography (according to the results from step 1). Next, we established 2 DIS versions according to the PV lesion cutoffs of $\geq 1$ and $\geq 3$. We then assessed the sensitivity, specificity, accuracy, positive predictive value, and negative predictive value of both DIS versions, first individually and then combined with DIT, with second attack at 10 years as the outcome. Finally, we evaluated the performance of $\geq 1$ and $\geq 3$ PV lesions as part of DIS alone and DIS plus DIT according to age (40-49, 30-39, 20-29, and $\leq 19$ years) and CIS topography (optic nerve, infratentorial, SC, and other, which can include multifocal or hemispheric syndromes).

Statistical tests were performed on the 0.05 level of significance using IBM SPSS Statistics (SPSS Inc., Chicago, IL), version 22.0 .

Standard protocol approvals, registrations, and patient consents. This study received approval from the Clinical Research Ethics Committee at Vall d'Hebron University Hospital. All patients signed written informed consents.

RESULTS From January 1995 to January 2016, we included 1,214 patients in the CIS cohort. Of these, we excluded $71(5.8 \%)$ during follow-up for having presented a previous demyelinating attack $(\mathrm{n}=13)$, exceeding the age limit $(n=4)$, exceeding the entry window $(\mathrm{n}=26)$, or reaching an alternative diagnosis $(\mathrm{n}=28)$. Of the remaining 1,143 patients, 657 fulfilled the criteria for step 1 and 326 fulfilled the criteria for step 2 .

Step 1. Baseline characteristics. Of the 657 patients, $66.5 \%$ were female, and they had a mean (SD) age of 32.2 (8.0) years. The baseline brain MRI was abnormal in $75.5 \%$. During a mean follow-up of 6.5 (4.2) years, $282(42.9 \%)$ presented a second attack (table 1$)$.

Effect of individual lesion topography classifications. Table 2 shows the number of patients fulfilling each type of lesion topography classification, the 
proportion presenting a second attack, and their corresponding hazard ratios $(95 \% \mathrm{CI})$. Both stepwise models confirmed the significant contributions of $\geq 1 \mathrm{PV}, \geq 1 \mathrm{CJC}$, and $\geq 1$ infratentorial lesions; $\geq 1$ SC lesions remained in the second to last backward step (1.5 [1.0-2.2]; $p=0.045)$. Bootstrap showed no overfitting in our models (bias from -0.008 to 0.009$)$.

Step 2. Baseline characteristics. Of the 326 patients, $69.6 \%$ were female, and they had a mean (SD) age of 31.5 (7.9) years; the baseline brain MRI was abnormal in $89.9 \%$. Gd enhancement was demonstrated in $39.0 \%$ of brain and $24.3 \%(n=28 / 115)$ of SC scans. During a mean follow-up of 9.0 (3.8) years, $86.5 \%$ presented a second demyelinating attack. Diseasemodifying treatment was started before the second attack in $31.0 \%$ (table 1 ). The proportion of patients treated before the second attack fulfilling DIS with $\geq 1$ PV lesions was similar to DIS with $\geq 3$ PV lesions (40.3\% and $42.5 \%$, respectively), and between DIS plus DIT with $\geq 1 \quad(51.6 \%)$ and $\geq 3$ PV lesions (52.4\%).

Performance of DIS and DIS plus DIT according to the PV lesion number cutoffs. Concerning the performance of the modified 2010 criteria, although the specificity of the criteria with $\geq 1$ PV lesions was slightly lower than with $\geq 3$ PV when assessing DIS (table 3), it was exactly the same after combining them with DIT (table 4).

When assessing age groups, $\geq 3 \mathrm{PV}$ lesions conferred a higher specificity to DIS than $\geq 1$ PV lesions in the 40-49 years of age bracket (table 3). This difference disappeared when evaluating DIS plus DIT (table 4). We observed a very similar pattern in optic neuritis when evaluating CIS topographies (tables e-1 and e-2 at Neurology.org).

DISCUSSION In step 1, the stepwise multivariable analyses selected CJC over JC lesions and thus we used the former topography in our DIS model for step 2. If also considering the univariable analyses and the similar proportion of patients with JC and CJC lesions presenting a second attack, our findings support the notion that the sharp differentiation between JC and intracortical lesions is not necessary, complying with the Magnetic Resonance Imaging in Multiple Sclerosis (MAGNIMS) consensus recommendation of combining them into a single term ${ }^{1}$ in specialized institutions where this is possible, whereas in other centers the determination of JC lesions could suffice. Nevertheless, a limitation of our study is our recent implementation of DIR (2010), which could lead to missing patients with intracortical lesions; hence, further studies are needed to validate these results. Concerning CC lesions, our negative results coincide with a previous study, ${ }^{7}$ even though in our case we did have sagittal images and T2-FLAIR sequences. Contrary to these findings, another study did show an effect of CC lesions but the individual contributions of each lesion topography were not taken into account, ${ }^{13}$ an important issue since different lesion topographies can coexist. Nonetheless, our negative results could be influenced by the lower number of patients with prospectively recorded CC lesion data. Another possible explanation is that CC lesions are less frequently associated with Gd enhancement than deep white matter lesions and, therefore, may not be good predictors for the development of a second attack. ${ }^{14}$ Another limitation in step 1 is the smaller sample size in the case of SC lesions.

Regarding PV lesions in step 1, the stepwise analyses favored $\geq 1$ PV over $\geq 3$ PV lesions. The MAGNIMS expert consensus proposed going back to the 3-lesion cutoff, 7 based on the detection of incidental PV lesions in healthy individuals and patients with other neurologic diseases, and on studies showing that this lesion threshold could help differentiate MS from other diseases. ${ }^{1}$ Although incidental PV lesions could

\begin{tabular}{|c|c|c|c|c|c|c|}
\hline \multirow[t]{2}{*}{ Table 2} & \multicolumn{6}{|c|}{ Proportions and hazard ratios (HRs) of the different lesion topographies $(n=657$ ) } \\
\hline & n (\%) & Second attack, $\mathrm{n}(\%)$ & $\begin{array}{l}\text { Univariable } \\
\text { HR }(95 \% \mathrm{Cl})\end{array}$ & p & $\begin{array}{l}\text { HR with forward and backward } \\
\text { stepwise analyses }(95 \% \mathrm{Cl})\end{array}$ & $p$ \\
\hline$\geq 1 \mathrm{PV}$ & $414(63.0)$ & $232 / 414(56.0)$ & $3.7(2.7-5.0)$ & $<0.0001$ & $2.5(1.7-3.6)$ & $<0.0001$ \\
\hline$\geq 3 \mathrm{PV}$ & $356(54.2)$ & $211 / 356(59.3)$ & $3.2(2.4-4.2)$ & $<0.0001$ & - & \\
\hline$\geq 1 \mathrm{JC}$ & 295 (44.9) & $172 / 295$ (58.3) & $2.5(2.0-3.2)$ & $<0.0001$ & - & \\
\hline$\geq 1 \mathrm{CJC}$ & $298(45.4)$ & $174 / 298(58.4)$ & $2.5(2.0-3.2)$ & $<0.0001$ & $1.4(1.0-1.8)$ & 0.025 \\
\hline$\geq 1 \mathrm{CC}$ & 187/433 (43.2) & $84 / 187$ (44.9) & $2.0(1.4-2.7)$ & $<0.0001$ & - & \\
\hline$\geq 1$ IT & 328 (49.9) & 191/328 (58.2) & $2.6(2.0-3.3)$ & $<0.0001$ & $1.4(1.1-1.9)$ & 0.013 \\
\hline$\geq 1 \mathrm{SC}$ & 172/329 (52.3) & 76/172 (44.2) & $2.2(1.5-3.3)$ & $<0.0001$ & - & \\
\hline
\end{tabular}

Abbreviations: $\mathrm{CC}=$ corpus callosum; $\mathrm{Cl}=$ confidence interval; $\mathrm{CJC}=$ cortico-juxtacortical; IT $=$ infratentorial; $\mathrm{JC}=$ juxtacortical; $\mathrm{PV}=$ periventricular; $\mathrm{SC}=$ spinal cord. Outcome: second attack. 


\begin{tabular}{|c|c|c|c|c|c|c|c|}
\hline \multirow[t]{2}{*}{ Table 3} & \multicolumn{7}{|c|}{ DIS performance in all cases and by age groups, according to the PV lesion cutoffs ( $\geq 1$ vs $\geq 3$ ) (total $n=326$ ) } \\
\hline & DIS, n (\%) & $\begin{array}{l}\text { Second attack in patients } \\
\text { with DIS, } \mathrm{n}(\%)\end{array}$ & $\begin{array}{l}\text { Sensitivity } \\
(95 \% \mathrm{Cl})\end{array}$ & $\begin{array}{l}\text { Specificity } \\
(95 \% \mathrm{Cl})\end{array}$ & $\begin{array}{l}\text { Accuracy } \\
(95 \% \mathrm{Cl})\end{array}$ & PPV (95\% Cl) & NPV (95\% Cl) \\
\hline All & $236 / 326(72.4)$ & 218/236 (92.4) & $77.3(72.0-82.1)$ & $59.1(43.3-73.7)$ & $74.8(69.8-79.5)$ & $92.4(89.4-94.6)$ & $28.9(22.7-36.0)$ \\
\hline $40-49$ y & $45 / 57(78.9)$ & $40 / 45(88.9)$ & $88.9(76.0-96.3)$ & $58.3(27.7-84.8)$ & $82.5(70.1-91.3)$ & $88.9(80.3-94.0)$ & $58.3(35.0-78.4)$ \\
\hline $20-29$ y & $97 / 130$ (74.6) & 90/97 (92.8) & $78.3(69.6-85.4)$ & $53.3(26.6-78.7)$ & $75.4(67.1-82.5)$ & $92.8(88.1-95.7)$ & $24.2(15.1-36.5)$ \\
\hline$\leq 19$ y & 10/17 (58.8) & $10 / 10(100.0)$ & $62.5(35.4-84.8)$ & $100.0(2.5-100.0)$ & 64.7 (38.3-85.8) & $100.0(69.2-100.0)$ & $14.3(8.1-23.9)$ \\
\hline \multicolumn{8}{|l|}{ DIS $\geq 3 \mathrm{PV}$} \\
\hline All & 221/326 (67.8) & 204/221 (92.3) & $72.3(66.7-77.5)$ & $61.4(45.5-75.6)$ & $70.9(65.6-75.7)$ & $92.3(89.1-94.6)$ & 25.7 (20.4-31.9) \\
\hline$\leq 19 y$ & $10 / 17(58.8)$ & $10 / 10(100.0)$ & $62.5(35.4-84.8)$ & $100.0(2.5-100.0)$ & 64.7 (38.3-85.8) & $100.0(69.2-100.0)$ & $14.3(8.1-23.9)$ \\
\hline
\end{tabular}

Abbreviations: $\mathrm{Cl}$ = confidence interval; DIS = dissemination in space; NPV = negative predictive value; PPV = positive predictive value; PV = periventricular.

Outcome: second attack at 10 years. Modifications to the criteria include symptomatic lesions and $\geq 1$ cortical and juxtacortical lesions.

also suggest a radiologically isolated syndrome, it is important to emphasize the role of specificity to minimize the risk of overdiagnosing MS, especially in older patients. Therefore, in step 2 we compared their performance, observing that in DIS, the $\geq 3$ cutoff was only $2.3 \%$ more specific than $\geq 1$. Furthermore, when evaluating DIS plus DIT, the diagnostic performance was practically the same for both. These results are in accordance with a more recent publication that studied the effect of a varying number of PV lesions in 151 patients with CIS. ${ }^{4}$ In addition, another study compared the performance of the 2010 McDonald criteria and the 2016 MAGNIMS proposal, observing an overall lower specificity for the latter, which includes $\geq 3$ PV lesions for DIS (63.1\% vs $46.4 \%$, respectively). ${ }^{15}$

However, when assessing age brackets in our study, the specificity gap increased to $8.4 \%$ favoring DIS with $\geq 3$ PV lesions in patients aged $40-49$ years. But once again, when assessing DIS plus DIT, we found no differences in specificity. The same occurred with optic neuritis cases when we assessed

Table 4 DIS plus DIT performance in all cases and by age groups, according to the PV lesion cutoffs $(\geq 1 \mathrm{vs} \geq 3)$ (total $n=326)$

\begin{tabular}{|c|c|c|c|c|c|c|c|}
\hline & $\begin{array}{l}\text { DIS + DIT, } \\
\text { n (\%) }\end{array}$ & $\begin{array}{l}\text { Second attack in } \\
\text { patients with } \\
\text { DIS + DIT, n (\%) }\end{array}$ & $\begin{array}{l}\text { Sensitivity } \\
(95 \% \mathrm{CI})\end{array}$ & $\begin{array}{l}\text { Specificity } \\
(95 \% \mathrm{Cl})\end{array}$ & Accuracy $(95 \% \mathrm{Cl})$ & PPV (95\% Cl) & NPV (95\% Cl) \\
\hline \multicolumn{8}{|c|}{ DIS + DIT $\geq 1 \mathrm{PV}$} \\
\hline All & 128/326 (39.3) & $123 / 128$ (96.1) & 43.6 (37.8-49.6) & 88.6 (75.4-96.2) & $49.7(44.1-55.3)$ & 96.1 (91.4-98.3) & $19.7(17.5-22.1)$ \\
\hline $40-49$ y & $23 / 57(40.4)$ & 21/23 (91.3) & 46.7 (31.7-62.1) & 83.3 (51.6-97.9) & $54.4(40.7-67.6)$ & 91.3 (74.0-97.5) & $29.4(22.3-37.7)$ \\
\hline $30-39 y$ & 39/122 (32.0) & $37 / 39$ (94.9) & 34.9 (25.9-44.8) & 87.5 (61.7-98.5) & 41.8 (32.9-51.1) & 94.9 (83.1-98.6) & $16.9(13.9-20.4)$ \\
\hline $20-29 y$ & $59 / 130(45.4)$ & $58 / 59$ (98.3) & 50.4 (41.0-59.9) & 93.3 (61.7-98.5) & $55.4(46.4-64.1)$ & 98.3 (89.6-99.7) & $19.7(16.4-23.6)$ \\
\hline$\leq 19 y$ & $7 / 17$ (41.2) & $7 / 7$ (100.0) & $43.8(19.8-70.1)$ & $100.0(2.5-100.0)$ & 47.1 (23.0-72.2) & $100.0(59.0-100.0)$ & $10.0(6.7-14.6)$ \\
\hline \multicolumn{8}{|c|}{ DIS + DIT $\geq 3$ PV } \\
\hline All & $126 / 326$ (38.7) & $121 / 126$ (96.0) & 42.9 (37.1-48.9) & 88.6 (75.4-96.2) & $49.1(43.5-54.6)$ & 96.0 (91.3-98.2) & 19.5 (17.3-21.9) \\
\hline $40-49$ y & $23 / 57(40.4)$ & 21/23 (91.3) & 46.7 (31.7-62.1) & 83.3 (51.6-97.9) & $54.4(40.7-67.6)$ & 91.3 (74.0-97.5) & $29.4(22.3-37.7)$ \\
\hline $30-39$ y & $38 / 122$ (31.1) & $36 / 38$ (94.7) & $34.0(25.0-43.8)$ & 87.5 (61.7-98.5) & 41.0 (32.2-50.3) & 94.7 (82.7-98.5) & $16.7(13.7-20.1)$ \\
\hline $20-29 y$ & $58 / 130(44.6)$ & $57 / 58$ (98.3) & $49.6(40.1-59.0)$ & 93.3 (68.1-99.8) & $54.6(45.7-63.4)$ & 98.3 (89.5-99.7) & $19.4(16.1-23.2)$ \\
\hline$\leq 19 y$ & $7 / 17$ (41.2) & $7 / 7$ (100.0) & 43.8 (19.8-70.1) & $100.0(2.5-100.0)$ & 47.1 (23.0-72.2) & $100.0(59.0-100.0)$ & $10.0(6.7-14.6)$ \\
\hline
\end{tabular}

Abbreviations: $\mathrm{Cl}=$ confidence interval; DIS = dissemination in space; DIT = dissemination in time; NPV = negative predictive value; PPV = positive predictive value; $\mathrm{PV}=$ periventricular.

Outcome: second attack at 10 years. Modifications to the criteria include symptomatic lesions and $\geq 1$ cortical and juxtacortical lesions. 
CIS topography. Altogether, these findings in patients with typical CIS suggest that, first, the presence of $\geq 1$ PV lesions already indicates an increased risk of presenting a second attack; second, their diagnostic specificity is high when combined with at least another typical topography; third, this specificity is only slightly inferior to $\geq 3$ PV lesions; and fourth, their specificity is the same if also considering DIT. The latter is particularly relevant when taking age into account, given that the difference in specificity favoring $\geq 3 \mathrm{PV}$ lesions in older patients disappears after adding DIT. Furthermore, this increased specificity in older patients can be explained by the fact that the presence of small, focal high-intensity areas surrounding the regions around the anterior and posterior pole of the lateral ventricles, and thin linear hyperintensities along the body of the lateral ventricles on T2weighted images, the so-called PV caps and bands, are a common finding in normal aging. ${ }^{16}$ However, these incidental findings are usually symmetric and not oval-shaped, and should not be confused with the PV lesions seen in MS.

As for the increased specificity of DIS with $\geq 3 \mathrm{PV}$ lesions in optic neuritis, previous studies demonstrated that the lower rate of second demyelinating attacks in this topography compared to others disappeared when selecting only the cases with abnormal brain MRIs ${ }^{17}$ or when including other risk factors in the analyses. ${ }^{8}$ Hence, the higher specificity observed in DIS with $\geq 3 \mathrm{PV}$ lesions could probably be influenced by a higher T2 lesion number at baseline. That the difference disappears when adding DIT underscores the importance of Gd-enhancing lesions for establishing MS diagnosis.

Importantly, we do not consider it practical to produce a different set of criteria for older patients or cases presenting with optic neuritis. Preferably, we should underscore that the McDonald criteria were outlined to be applied in patients we suspect might have MS and that we should always ensure there is no better diagnostic explanation for the clinical presentation.

Therefore, maintaining the current threshold of $\geq 1 \mathrm{PV}$ lesions in the McDonald criteria does not compromise specificity in typical CIS cases, but special attention should be paid to older patients and optic neuritis cases.

\section{AUTHOR CONTRIBUTIONS}

Georgina Arrambide contributed to the concept and design of the work; acquisition, analysis, and interpretation of data for the work; participated in the drafting of the work and revised it for important intellectual content; and gave final approval of the version to be published. Mar Tintore contributed to the concept and design of the work; acquisition, analysis, and interpretation of data for the work; participated in the drafting of the work and revised it for important intellectual content; and gave final approval of the version to be published. Cristina Auger contributed to the acquisition and analysis of data for the work; participated in the revision of the manuscript for important intellectual content; and gave final approval of the version to be published. Jordi Río contributed to the acquisition and analysis of data for the work; participated in the drafting of the work and revised it for important intellectual content; and gave final approval of the version to be published. Joaquín Castilló contributed to the acquisition and analysis of data for the work; participated in the drafting of the work and revised it for important intellectual content; and gave final approval of the version to be published. Angela Vidal-Jordana contributed to the acquisition and analysis of data for the work; participated in the drafting of the work and revised it for important intellectual content; and gave final approval of the version to be published. Ingrid Galán contributed to the acquisition and analysis of data for the work; participated in the drafting of the work and revised it for important intellectual content; and gave final approval of the version to be published. Carlos Nos contributed to the acquisition and analysis of data for the work; participated in the drafting of the work and revised it for important intellectual content; and gave final approval of the version to be published. Manuel Comabella contributed to the acquisition and analysis of data for the work; participated in the drafting of the work and revised it for important intellectual content; and gave final approval of the version to be published. Raquel Mitjana contributed to the acquisition and analysis of data for the work; participated in the revision of the manuscript for important intellectual content; and gave final approval of the version to be published. Patricia Mulero contributed to the acquisition and analysis of data for the work; participated in the drafting of the work and revised it for important intellectual content; and gave final approval of the version to be published. Andrea de Barros contributed to the acquisition and analysis of data for the work; participated in the revision of the manuscript for important intellectual content; and gave final approval of the version to be published. Breogán Rodríguez-Acevedo contributed to the acquisition and analysis of data for the work; participated in the drafting of the work and revised it for important intellectual content; and gave final approval of the version to be published. Luciana Midaglia contributed to the acquisition and analysis of data for the work; participated in the drafting of the work and revised it for important intellectual content; and gave final approval of the version to be published. Jaume Sastre-Garriga contributed to the acquisition, analysis, and interpretation of data for the work; participated in the drafting of the work and revised it for important intellectual content; and gave final approval of the version to be published. Alex Rovira contributed to the acquisition, analysis, and interpretation of data for the work; participated in the drafting of the work and revised it for important intellectual content; and gave final approval of the version to be published. Xavier Montalban contributed to the concept and design of the work; acquisition, analysis, and interpretation of data for the work; participated in the drafting of the work and revised it for important intellectual content; and gave final approval of the version to be published.

\section{ACKNOWLEDGMENT}

The authors thank Susana Otero (Department of Epidemiology and Servei de Neurologia-Neuroimmunologia, Centre d'Esclerosi Múltiple de Catalunya, Vall d'Hebron University Hospital, Barcelona, Spain) and Santiago Pérez-Hoyos (Statistics and Bioinformatics Unit, Vall d'Hebron Institut de Recerca, Barcelona, Spain) for statistical analysis support.

\section{STUDY FUNDING}

This project was supported by the "Fondo de Investigación Sanitaria" (FIS) of the Ministry of Economy and Competitiveness of Spain (grant PI14/01439 awarded to X.M.). Angela Vidal-Jordana received support for research training contracts "Rio Hortega" (CM10/00032) from the FIS, Instituto de Salud Carlos III, Ministry of Economy and Competitiveness of Spain. The "Red Española de Esclerosis Múltiple" (RD07/0060; RD12/0032) was sponsored by the FIS, the Instituto de Salud Carlos III, the Ministry of Economy and Competitiveness in Spain, and the "Ajuts per donar Suport als Grups de Recerca de Catalunya” (2009 SGR 0793; 2014 SGR 1082) sponsored by the "Agència de Gestió d'AjutsUniversitaris i de Recerca" of the Generalitat de Catalunya in Spain.

\section{DISCLOSURE}

G. Arrambide has received compensation for consulting services from Biogen-Idec, research support from Novartis, and speaking honoraria from Sanofi-Aventis. M. Tintore has received compensation for consulting services and speaking honoraria from Bayer Schering Pharma, 
Merck-Serono, Biogen-Idec, Teva Pharmaceuticals, Sanofi-Aventis, Novartis, Almirall, Genzyme, and Roche. C. Auger has received speaking honoraria from Novartis, Biogen, and Stendhal. J. Río has received speaking honoraria and personal compensation for participating on advisory boards from Almirall, Bayer-Schering Healthcare, Biogen-Idec, Genzyme, MerckSerono, Novartis, Teva, and Sanofi-Aventis. J. Castilló reports no disclosures relevant to the manuscript. A. Vidal-Jordana has received speaking honoraria and consulting fees from Novartis, Roche, and Sanofi-Aventis. I. Galán reports no disclosures relevant to the manuscript. C. Nos has received funding for travel from Biogen Idec and F. Hoffmann-La Roche, Ltd., and speaker honoraria from Novartis. M. Comabella has received compensation for consulting services and speaking honoraria from Bayer Schering Pharma, Merck Serono, Biogen-Idec, Teva Pharmaceuticals, Sanofi-Aventis, and Novartis. R. Mitjana, P. Mulero, A. de Barros, B. Rodríguez-Acevedo, and L. Midaglia report no disclosures relevant to the manuscript. J. Sastre-Garriga has received compensation for participating on advisory boards, speaking honoraria, and travel expenses for scientific meetings, consulting services or research support from Celgene, Novartis, Biogen, Teva, Merck, Almirall, and Genzyme. A. Rovira serves on scientific advisory boards for Biogen Idec, Novartis, Genzyme, and OLEA Medical, and on the editorial board of the American Journal of Neuroradiology, Neuroradiology, and European Radiology; has received speaker honoraria from Bayer, Genzyme, Sanofi-Aventis, Bracco, Merck-Serono, Teva Pharmaceutical Industries Ltd, OLEA Medical, Stendhal, Novartis, and Biogen Idec; and has research agreements with Siemens AG. X. Montalban has received speaking honoraria and travel expenses for participation in scientific meetings, and has been a steering committee member of clinical trials or participated in advisory boards of clinical trials in the past with Actelion, Amirall, Bayer, Biogen, Celgene, Genzyme, Hoffmann-La Roche, Novartis, Oryzon Genomics, Sanofi-Genzyme, and Teva Pharmaceutical. Go to Neurology.org for full disclosures.

Received April 27, 2017. Accepted in final form August 30, 2017.

\section{REFERENCES}

1. Filippi M, Rocca MA, Ciccarelli O, et al. MRI criteria for the diagnosis of multiple sclerosis: MAGNIMS consensus guidelines. Lancet Neurol 2016;15:292-303.

2. Tintore M, Rovira A, Arrambide G, et al. Brainstem lesions in clinically isolated syndromes. Neurology 2010;75: 1933-1938.

3. Arrambide G, Rovira A, Sastre-Garriga J, et al. Spinal cord lesions: a modest contributor to diagnosis in clinically isolated syndromes but a relevant prognostic factor. Mult Scler Epub 2017 Mar 1.

4. Brownlee WJ, Miszkiel KA, Altmann DR, Ciccarelli O, Miller DH. Periventricular lesions and MS diagnostic criteria in young adults with typical clinically isolated syndromes. Mult Scler 2017;23:1031-1034.
5. Filippi M, Rocca MA, Calabrese M, et al. Intracortical lesions: relevance for new MRI diagnostic criteria for multiple sclerosis. Neurology 2010;75:1988-1994.

6. Geurts JJ, Roosendaal SD, Calabrese M, et al. Consensus recommendations for MS cortical lesion scoring using double inversion recovery MRI. Neurology 2011;76: 418-424.

7. Barkhof F, Filippi M, Miller DH, et al. Comparison of MRI criteria at first presentation to predict conversion to clinically definite multiple sclerosis. Brain 1997;120: 2059-2069.

8. Tintore M, Rovira A, Rio J, et al. Defining high, medium and low impact prognostic factors for developing multiple sclerosis. Brain 2015;138:1863-1874.

9. Swanton JK, Rovira A, Tintore M, et al. MRI criteria for multiple sclerosis in patients presenting with clinically isolated syndromes: a multicentre retrospective study. Lancet Neurol 2007;6:677-686.

10. Polman $\mathrm{CH}$, Reingold SC, Banwell B, et al. Diagnostic criteria for multiple sclerosis: 2010 revisions to the McDonald criteria. Ann Neurol 2011;69:292-302.

11. Tintore M, Otero-Romero S, Rio J, et al. Contribution of the symptomatic lesion in establishing MS diagnosis and prognosis. Neurology 2016;87:1368-1374.

12. Brownlee WJ, Swanton JK, Miszkiel KA, Miller DH, Ciccarelli O. Should the symptomatic region be included in dissemination in space in MRI criteria for MS? Neurology 2016;87:680-683.

13. Jafari N, Kreft KL, Flach HZ, Janssens AC, Hintzen RQ. Callosal lesion predicts future attacks after clinically isolated syndrome. Neurology 2009;73:1837-1841.

14. Garg N, Reddel SW, Miller DH, et al. The corpus callosum in the diagnosis of multiple sclerosis and other CNS demyelinating and inflammatory diseases. J Neurol Neurosurg Psychiatry 2015;86:1374-1382.

15. Hyun JW, Huh SY, Kim W, et al. Evaluation of the 2016 MAGNIMS MRI criteria for dissemination in space in patients with a clinically isolated syndrome. Mult Scler Epub 2017 May 1.

16. Zimmerman RD, Fleming CA, Lee BC, Saint-Louis LA, Deck MD. Periventricular hyperintensity as seen by magnetic resonance: prevalence and significance. AJR Am J Roentgenol 1986;146:443-450.

17. Tintore M, Rovira A, Rio J, et al. Is optic neuritis more benign than other first attacks in multiple sclerosis? Ann Neurol 2005;57:210-215.

\section{Our Guidelines. Your Language.}

Selected AAN evidence-based clinical practice guidelines are available in Arabic, Chinese, Hungarian, Japanese, Korean, Polish, Spanish, and Turkish languages, making it easier for you to provide high-quality care for your patients. Visit AAN.com/view/MultipleLanguages. 


\section{Neurology}

Lesion topographies in multiple sclerosis diagnosis: A reappraisal

Georgina Arrambide, Mar Tintore, Cristina Auger, et al.

Neurology 2017;89;2351-2356 Published Online before print November 3, 2017

DOI 10.1212/WNL.0000000000004715

This information is current as of November 3, 2017

\section{Updated Information \& Services \\ Supplementary Material}

\section{References}

Citations

Subspecialty Collections

Permissions \& Licensing

Reprints including high resolution figures, can be found at:

http://n.neurology.org/content/89/23/2351.full

Supplementary material can be found at:

http://n.neurology.org/content/suppl/2017/11/03/WNL.0000000000004 715.DC1

http://n.neurology.org/content/suppl/2017/11/03/WNL.0000000000004 715.DC2

This article cites 15 articles, 6 of which you can access for free at: http://n.neurology.org/content/89/23/2351.full\#ref-list-1

This article has been cited by 5 HighWire-hosted articles: http://n.neurology.org/content/89/23/2351.full\#\#otherarticles

This article, along with others on similar topics, appears in the following collection(s):

\section{MRI}

http://n.neurology.org/cgi/collection/mri

Multiple sclerosis

http://n.neurology.org/cgi/collection/multiple_sclerosis

Information about reproducing this article in parts (figures,tables) or in its entirety can be found online at:

http://www.neurology.org/about/about_the_journal\#permissions

Information about ordering reprints can be found online:

http://n.neurology.org/subscribers/advertise

Neurology ${ }^{\circledR}$ is the official journal of the American Academy of Neurology. Published continuously since 1951, it is now a weekly with 48 issues per year. Copyright Copyright ( 2017 The Author(s). Published by Wolters Kluwer Health, Inc. on behalf of the American Academy of Neurology.. All rights reserved. Print ISSN: 0028-3878. Online ISSN: 1526-632X.

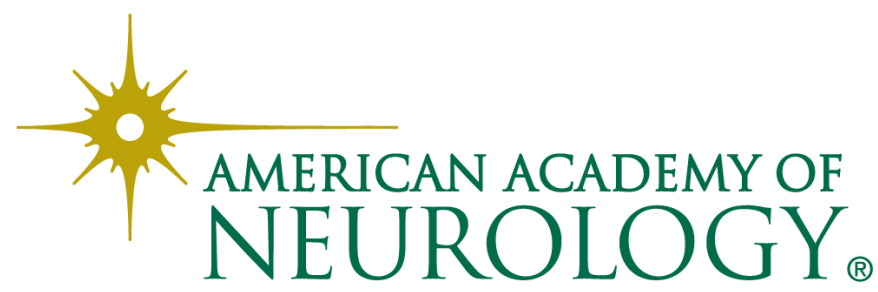

